\title{
In vitro and in vivo anti-Trypanosoma brucei activities of phenazinomycin and related compounds
}

\author{
The Journal of Antibiotics (2010) 63, 579-581; doi:10.1038/ja.2010.72; published online 30 June 2010
}

During the course of our screening program to discover new antitrypanosomal compounds, we have evaluated isolates from soil microorganisms as well as compounds from the antibiotic libraries of the Kitasato Institute for Life Sciences and Bioscience Associates. We have previously reported on various microbial metabolites exhibiting potent antiTrypanosoma brucei properties, which are defined as antitrypanosomal properties. ${ }^{1,2}$ We have recently evaluated the known phenazine antibiotics, phenazinomycin, griseoluteic acid, griseolutein B and related compounds, some of which have shown significant antitrypanosomal activities, both in vitro and in vivo. Here, we report the antitrypanosomal profiles of phenazinomycin and some related compounds (Figure 1) in comparison with those of some clinically used antitrypanosomal drugs, such as suramin and eflornithine. We also present our findings with respect to structure-activity relationships.

Griseoluteic acid, griseolutein B, phenazinomycin and 1,6-dimethoxyphenazine were obtained from the antibiotic libraries of the Kitasato Institute for Life Sciences and Bioscience Associates. Related compounds, namely clinically used clofazimine and phenazine, were purchased from Sigma (SigmaAldrich, St Louis, MO, USA), and phenazine 5-oxide was donated by Meiji Seika Kaisha (Yokohama, Japan).

In vitro antitrypanosomal activities against Trypanosoma brucei brucei strain GUTat 3.1 (low virulence strain against mice) and cytotoxicity against human diploid embryonic cell line MRC-5 were measured, as described previously. ${ }^{1,3}$ In vivo antitrypanosomal activity for T. $b$. brucei strain S427 (high virulence strain against mice) was measured as described previously. ${ }^{2}$ Test compounds were solubilized in an aqueous mixture of $10 \%$ DMSO-Tween 80 and EtOH (7:3) and admi- nistered i.p. to mice on the next day (day 1) following infection with parasites (day 0 ). Subsequently, the compounds were successively administered (i.p.) to the infected mice once a day for 3 days (days 2-4). Efficacies of the compounds were determined by parasitaemia levels and the mean of survival days (MSD), and compared with those of the untreated control mice.

Table 1 shows the in vitro antitrypanosomal activities of phenazine compounds and selected standard antitrypanosomal drugs. Griseolutein B showed the highest antitrypanosomal activity, with an $\mathrm{IC}_{50}$ value of $1.4 \mathrm{ng} \mathrm{ml}^{-1}$. The compound was $1100-1600-$ fold more potent than eflornithine and suramin. Phenazinomycin was 164-fold less active than griseolutein $\mathrm{B}$, showing an $\mathrm{IC}_{50}$ value of $230 \mathrm{ng} \mathrm{ml}^{-1}$. Griseoluteic acid and clofazimine showed moderate antitrypanosomal activity, with an $\mathrm{IC}_{50}$ value of approximately $2 \mu \mathrm{g} \mathrm{ml}^{-1}$, which is comparable to those of both eflornithine and suramin, whereas 1,6-demethoxyphenazine, phenazine and phenazine 5-oxide showed no antitrypanosomal activity whatsoever.

The in vitro cytotoxicities of phenazine compounds and the antitrypanosomal drugs tested are also presented in Table 1. Griseolutein B showed the highest cytotoxicity against MRC-5 cells, with an $\mathrm{IC}_{50}$ value of $9 \mathrm{ng} \mathrm{ml}^{-1}$. Griseoluteic acid and phenazinomycin were revealed to be slightly cytotoxic, demonstrating $\mathrm{IC}_{50}$ values of $5-6 \mu \mathrm{g} \mathrm{ml}^{-1}$, while clofazimine had an $\mathrm{IC}_{50}$ value of $>100 \mu \mathrm{g} \mathrm{ml}^{-1}$ and was shown to be not cytotoxic.

For appropriate evaluation of the combined antitrypanosomal activities and cytotoxicities of test compounds, we introduced selectivity indexes (SI; cytotoxicity $\left(\mathrm{IC}_{50}\right.$ for the MRC-5 cells)/antitrypanosomal activity ( $\mathrm{IC}_{50}$ for the GUTat 3.1 strain)) as presented in Table 1. Among the tested compounds, phenazinomycin and clofazimine showed a medium SI, with ratios of around $23->52$, less than or similar to those of eflornithine and suramin. Griseoluteic acid and griseolutein B showed a low SI, with ratios of around 3-6. Therefore, we selected phenazinomycin and clofazimine for in vivo efficacy tests.

The preliminary in vivo antitrypanosomal activities of phenazinomycin and clofazimine were measured in the T. b. brucei $\mathrm{S} 427$ acute mouse model. At a dose of $50 \mathrm{mg} \mathrm{kg}^{-1}$, phenazinomycin did not achieve cure but did extend the MSD to 12.3 days, representing a 2.7-fold increase over control MSD (4.5 days). The same dose of clofazimine did not achieve cure but also extended the MSD to 6.0 days, similar to the control MSD (6.0 days). Under the same conditions, suramin showed a curative effect (MSD: $>30$ days) at a much lower dose of $1 \mathrm{mg} / \mathrm{kg}$. The phenazinomycin data suggest that it might be a candidate compound for discovering new antitrypanosomal drugs. These efficacy tests, including in vivo antitrypanosomal activity, are ongoing.

1,6-Dimethoxyphenazine, phenazine and phenazine 5-oxide showed no antitrypanosomal activity. The most potent antitrypanosomal activity of griseolutein B and the moderate antitrypanosomal activity of griseoluteic acid and clofamizine, in comparison with phenazinomycin, provide very interesting information about structure-activity relationships. Griseoluteic acid lacks the substituent at N-5 and is 1450- and 9-fold less bioactive than griseolutein $\mathrm{B}$ and phenazinomycin, respectively. Furthermore, phenazinomycin possesses a substituent containing a sesquiterpene moiety at $\mathrm{N}-5$, and has a medium SI compared with griseoluteic acid and griseolutein B. Our data therefore suggest 


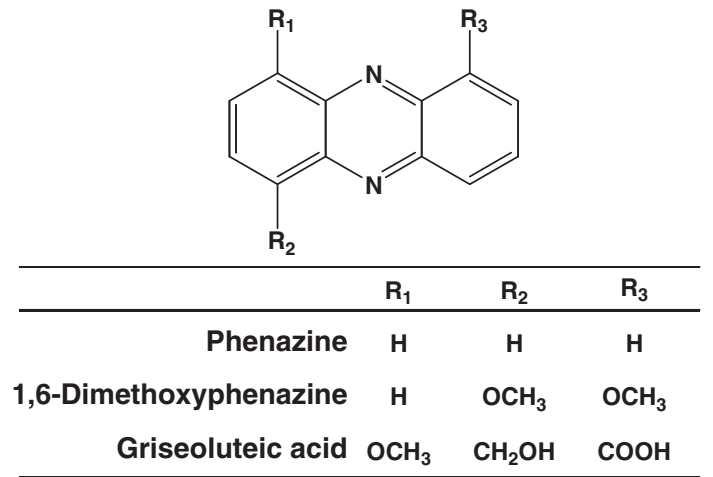

(c)

Phenazine 5-oxide<smiles>C=C1CCCC(C)(C)[C@@H]1CC/C(C)=C/Cn1c2cccc(=O)c-2nc2ccccc21</smiles>

Phenazinomycin<smiles>C#Cc1cccc2c1nc1c(OC)ccc(C(=O)O)c1[n+]2C(=O)CO</smiles>

Griseolutein B<smiles>CC(C)/N=c1/cc2n(-c3ccc(Cl)cc3)c3ccccc3nc-2cc1Nc1ccc(Cl)cc1</smiles>

Clofazimine

Figure 1 Structures of phenazine compounds.

that the substituent at N-5 present in phenazinomycin bestows significant antitrypanosomal activity and cytotoxicity.

Further studies are necessary for an extensive structure-in vitro antitrypanosomal activity evaluation of phenazinomycin-related compounds.

Griseoluteic acid (LL-141352beta) is known to have antitumor and weak antibacterial activity, through its mode of action in inhibition of DNA synthesis. ${ }^{4}$ Griseolutein B represents an equilibrium between the ketone form and the cyclic hemiacetal form (Figure 1), ${ }^{5}$ and is reported to have antibacterial and antitumor activity. ${ }^{6,7}$ We previously reported that phenazinomycin has antibacterial and antitumor activity, ${ }^{8}$ although the mode of action is not clearly understood. However, a related antibiotic, lavanducyanin (WS-9659 A), containing a cyclohexenylmethyl moiety at $\mathrm{N}-5$, is reported to have antitumor activity and to inhibit testosterone $5 \alpha$-reductase in rat, dog and human prostates. ${ }^{9,10}$ The mode of action of lavanducyanin is believed to be via disruption of signal transduction in cell growth. ${ }^{11}$ Clofazimine, an anti-inflammatory and antileprosy drug, is a riminophenazine compound and demonstrates antituberculosis and anti-Mycobacterium avium complex activities, while also being used to treat several diseases, including

Table 1 In vitro antitrypanosomal activity against Trypanosoma brucei brucei GUTat 3.1 and cytotoxicity in MRC- 5 cells of phenazine compounds and some commonly used antitrypanosomal drugs

\begin{tabular}{|c|c|c|c|}
\hline \multirow[b]{3}{*}{ Compound } & \multicolumn{2}{|c|}{$I_{50}\left(n g m I^{-1}\right)$} & \multirow{3}{*}{$\begin{array}{c}\text { Selectivity index (SI) } \\
\text { MRC-5/GUTat } 3.1\end{array}$} \\
\hline & Antitrypanosomal activity & Cytotoxicity & \\
\hline & GUTat 3.1 & $M R C-5$ & \\
\hline Griseoluteic acid & 2030 & 6110 & 3 \\
\hline Griseolutein B & 1.4 & 9 & 6 \\
\hline Phenazinomycin & 230 & 5190 & 23 \\
\hline 1,6-Dimethoxyphenazine & $>12500$ & $N D^{a}$ & - \\
\hline Clofazimine & 1920 & $>100000$ & $>52$ \\
\hline Phenazine & $>12500$ & $N D^{a}$ & - \\
\hline Phenazine 5-oxide & $>12500$ & $N D^{a}$ & - \\
\hline Suramin & 1580 & $>100000$ & $>63$ \\
\hline Eflornithine & 2270 & $>100000$ & $>44$ \\
\hline
\end{tabular}

aNot determined.

leishmaniasis. ${ }^{12}$ The modes of action of clofazimine are via inhibition of DNA synthesis and stimulation of phospholipase $\mathrm{A}_{2} \cdot{ }^{12}$ The reported mechanisms of action of gliseoluteic acid, griseolutein B and clofazimine may be replicated against Trypanosoma too.

Recently, phenazine compounds have been reviewed extensively, as they are producers of reactive oxygen species, and also with a view to identifying their biochemical communication systems in soil or in mammals with bacterial infections. ${ }^{13}$ However, discovery of the antitrypanosomal activities of griseoluteic acid, griseolutein B, phenazinomycin and clofazimine is novel and our data constitute the first report of such properties.

The above results reveal that phenazinomycin is a candidate compound for development of novel antitrypanosomal drugs. Further study of the antitrypanosomal and other biological activities of phenazinomycin is in progress. 


\section{Acknowledgements}

This work was supported, in part, by funds from the Drugs for Neglected Diseases initiative (DNDi), Quality Assurance Framework of Higher Education from the Ministry of Education, Culture, Sports, Science and Technology, Japan (MEXT), and the All Kitasato Project Study (AKPS). We are grateful to Ms H Sekiguchi and Mr T Furusawa for their technical assistance.

Kazuhiko Otoguro $^{1}$, Aki Ishiyama ${ }^{1}$, Masato Iwatsuki ${ }^{1}$, Miyuki Namatame ${ }^{1}$,

Aki Nishihara-Tukashima ${ }^{1}$,

Takuji Nakashima ${ }^{2}$, Seiji Shibahara ${ }^{3}$,

Shinichi Kondo ${ }^{4}$, Haruki Yamada ${ }^{2}$ and Satoshi Ōmura ${ }^{2}$

${ }^{1}$ Research Center for Tropical Diseases, Kitasato Institute for Life Sciences, Kitasato University, Tokyo, Japan; ${ }^{2}$ Kitasato Institute for Life Sciences, Graduate School of Infection Control
Sciences, Kitasato University, Tokyo, Japan; ${ }^{3}$ Nimura Genetic Solutions, Tokyo, Japan and ${ }^{4}$ Bioscience Associates, Tokyo, Japan E-mails: otoguro@lisci.kitasato-u.ac.jp or omuras@insti.kitasato-u.ac.jp

1 Otoguro, K. et al. Selective and potent in vitro antitrypanosomal activities of 10 microbial metabolites. J. Antibiot. 61, 372-378 (2008).

2 Ishiyama, A. et al. In vitro and in vivo antitrypanosomal activities of two microbial metabolites, KS-505a and Alazopeptin. J. Antibiot. 61, 627-632 (2008).

3 Otoguro, K. Potent antimalarial activities of the polyether antibiotic, X-206. J. Antibiot. 54, 658-663 (2001).

4 Singh, M. Y. et al. Biological and mechanistic activities of phenazine antibiotics produced by culture LL14I352. J. Antibiot. 50, 785-787 (1997).

5 Challand, S. R., Herbert, R. B. \& Holliman, F. G. A new phenazine synthesis. The synthesis of griseoluteic acid, griseolutein A, and methyl diacetyl griseolutein B. J. Chem. Soc. (D) 34, 1423-1425 (1970).
6 Ōsato, T., Maeda, K. \& Umezawa, H. The existence of griseolutein A and B. J. Antibiot. Ser. A 7, 15-16 (1954).

7 Ogata, Y. Biological, studies on the antibiotics produced by Streptomyces griseoluteus. III. J. Antibiot. Ser. A 12, 133-141 (1959).

8 Ōmura, S. et al. Studies on a novel antitumor antibiotic, phenazinomycin: taxonomy, fermentation, isolation, and physico-chemical and biological characteristics. J. Antibiot. 42, 1037-1042 (1989).

9 Imai, S., Furihata, K., Hayakawa, Y., Noguchi, T. \& Seto, H. Lavanducyanin, a new antitumor substance produced by Streptomyces sp. J. Antibiot. 42, 1196-1198 (1989).

10 Nakayama, O. et al. WS-9659 A and B, novel testosterone $5 \alpha$-reductase inhibitors isolated from a Streptomyces III. Biological characteristics and pharmacological characteristics. J. Antibiot. 42, 1235-1240 (1989).

11 Matsumoto, M. \& Seto, H. Stimulation of mammalian cell proliferation by lavanducyanin. J. Antibiot. 44, 1471-1473 (1991).

12 Reddy, V. M., O'Sullivan, J. F. \& Gangadharam, P. R. J. Antimycobacterial activities of riminophenazines. J. Antibiot. Chemother. 43, 615-623 (1999).

13 Price-Whelan, A., Dietrich, L. E. \& Newmann, D. K. Rethinking 'secondary' metabolism: physiological roles for phenazine antibiotics. Nat. Chem. Biol. 2, 71-78 (2006). 